\title{
The monomeric GTPase RabA2 is required for progression and maintenance of membrane integrity of infection threads during root nodule symbiosis
}

\author{
Virginia Dalla Via ${ }^{1}$ Soledad Traubenik ${ }^{1}$ - Claudio Rivero ${ }^{1}$ O. Mario Aguilar ${ }^{1}$. \\ María Eugenia Zanetti ${ }^{1}$ - Flavio Antonio Blanco ${ }^{1}[\mathbb{D}$
}

Received: 28 October 2016 / Accepted: 21 December 2016 / Published online: 10 January 2017

(C) Springer Science+Business Media Dordrecht 2017

\begin{abstract}
Key message Progression of the infection canal that conducts rhizobia to the nodule primordium requires a functional Rab GTPase located in Golgi/trans-Golgi that also participate in root hair polar growth.

Abstract Common bean (Phaseolus vulgaris) symbiotically associates with its partner Rhizobium etli, resulting in the formation of root nitrogen-fixing nodules. Compatible bacteria can reach cortical cells in a tightly regulated infection process, in which the specific recognition of signal molecules is a key step to select the symbiotic partner. In this work, we show that RabA2, a monomeric GTPase from common bean, is required for the progression of the infection canal, referred to as the infection thread (IT), toward the cortical cells. Expression of miss-regulated mutant variants of RabA2 resulted in an increased number of abortive infection events, including bursting of ITs and a reduction in the number of nodules. Nodules formed in these plants were small and contained infected cells with disrupted symbiosome membranes, indicating either early senescence of these cells or defects in the formation of the symbiosome membrane during bacterial release. RabA2 localized to mobile vesicles around the IT, but mutations that affect GTP hydrolysis or GTP/GDP exchange
\end{abstract}

Electronic supplementary material The online version of this article (doi:10.1007/s11103-016-0581-5) contains supplementary material, which is available to authorized users.

Flavio Antonio Blanco

fablanco@biol.unlp.edu.ar

1 Instituto de Biotecnología y Biología Molecular, Facultad de Ciencias Exactas, Universidad Nacional de La Plata, Centro Científico y Tecnológico-La Plata, Consejo Nacional de Investigaciones Científicas y Técnicas, calle 115 y 49 s/n, CP 1900 La Plata, Argentina modified this localization. Colocalization of RabA2 with ArfA1 and a Golgi marker indicates that RabA2 localizes in Golgi stacks and the trans-Golgi network. Our results suggest that RabA2 is part of the vesicle transport events required to maintain the integrity of the membrane during IT progression.

Keywords Nitrogen fixation - Vesicle transport . Legume $\cdot$ Rhizobia $\cdot$ Nodulation

\section{Introduction}

Nitrogen can be incorporated into ecosystems as the result of biological interactions, such as the root endosymbiosis established between legume plants and diazotroph soil bacteria called rhizobia. This specific interaction is initiated by the exchange of molecular signals between plants and rhizobia, triggering two independent genetic programs in the root, the organogenesis of the nodule and the infection, in which bacteria transverse the epidermis to reach the dividing cortical cells. The infection is a highly controlled process that allows the selection of the specific symbiotic partner and the exclusion of pathogens. Once bacteria reach the nodule, they are allocated into specialized membrane surrounded intracellular compartments, the symbiosomes, where they convert $\mathrm{N}_{2}$ to molecules that can be incorporated into the plant metabolism (Oldroyd and Downie 2008).

In most legumes, perception of molecular signals from rhizobia produces changes in the cytoskeleton and the reorientation of the root hair polar growth to form a curl that entraps the attached rhizobia forming an infection focus (Esseling et al. 2003). Radial expansion of these infection foci forms an infection chamber, from which rhizobia 
are internalized via a tubular structure called the infection thread (IT) (Jones et al. 2007; Fournier et al. 2015). The IT is an inward growing structure derived from the infection chamber membrane, where occupying rhizobia reproduce by clonal divisions (Fournier et al. 2008, 2015; Murray et al. 2011). Elongation of the IT through the root hair requires transport of plant plasma membrane components, cell wall material and specialized matrix proteins by an active traffic of vesicles to the growing IT tip (Timmers et al. 1999; Gage 2004; Fournier et al. 2008, 2015). ITs continue elongating toward the cortical cells and reach nodule primordia, where bacteria are internalized to form symbiosomes and differentiate into nitrogen fixing bacteroids (van Brussel et al. 1992; Timmers et al. 1999). In the last years, genes encoding proteins involved directly or indirectly in the formation and/or progression of the IT have been reported, mainly related to cytoskeleton rearrangement, such as Nck-associated protein 1 (NAP1), 121F-specific p53 inducible RNA (PIR1) and Actin-related protein complex 1 (ARPC1), which promote actin nucleation acting via the Suppressor of cAMP receptor defect/ WASP family verprolin-homologous protein (SCAR/ WAVE) complex (Yokota et al. 2009; Miyahara et al. 2010; Hossain et al. 2012; Fournier et al. 2015). More recently, Qiu et al. (2015) identified a new SCAR protein, SCARN (SCAR for Nodulation), which is required for formation of ITs and their progression to the root cortex. In addition, a nodule pectate lyase is also required for IT formation, presumably locally degrading the plant cell wall to allow initiation of ITs (Xie et al. 2012). However, the knowledge of the molecular mechanisms that mediate cytoskeleton rearrangements and traffic of vesicles involved in plasma membrane and cell wall remodeling is still very limited.

GTPases are key components of the vesicle transport system that allows the sorting and delivery of molecules to different cellular compartments, including endomembrane trafficking, membrane recycling, endocytosis and exocytosis. They act as molecular switches that fluctuate between an inactive guanosine diphosphate (GDP) — bound form and an active guanosine triphosphate (GTP) - bound state, regulating vesicle budding from a donor membrane, vesicle transport, tethering and fusion to a target membrane (Grosshans et al. 2006). These events are required not only for housekeeping functions, but also for polar cell growth, such as pollen tube elongation and root hair development (Jones et al. 2002; Preuss et al. 2004; Surpin and Raikhel 2004; de Graaf et al. 2005). Polar growth and vesicle trafficking are also required for early stages of root nodule symbiosis, when actively growing root hairs change their growth axis, curl and entrap the bacteria, but also at later stages during formation of the symbiosome membrane. Monomeric GTPases are included in the RAS superfamily, which is subdivided into five main families: Ras, Rab, Arf, Ran and Rho. Participation of GTPases in symbiosis was first established in soybean, where it was shown that two Rab proteins are required for the formation of the symbiosome membrane (Cheon et al. 1993). Later on, a Rab from M. truncatula was shown to be required for maturation of the symbiosome (Limpens et al. 2009). Other GTPases belonging to the Rop (Rho of Plants) subfamily of RAS GTPases have also been associated to the nodulation process (Ke et al. 2012; Kiirika et al. 2012). In a previous work, we have reported that knockdown of the monomeric GTPase RabA2 from common bean (Phaseolus vulgaris) impaired not only root hair formation and growth, but also preinfection events of symbiosis (Blanco et al. 2009). Silencing of RabA2 by RNAi prevented root hair curling, IT formation and the induction of early nodulin-encoding genes, thus RabA2 RNAi roots did not form nodules. RabA2 was localized to moving vesicles in the periphery of root hairs. In response to rhizobia, when the polar growth of root hairs is reoriented to entrap rhizobia, RabA2 vesicles concentrated at the tip of root hairs, where the new axis of growth is established. These evidences reveled a connection between vesicle trafficking associated to polar growth and early molecular and morphological changes associated to nodulation, providing evidence to the hypothesis that vesicle movement acts upstream of the nodulation signaling pathway (Esseling et al. 2003). Due to the severe phenotype produced by RabA2 RNAi post-transcriptional silencing, it was not possible to evaluate by this genetic approach the role of RabA2 in downstream events, such as IT formation and elongation. In addition, overexpression of a wild type form of RabA2 did not reveal any noticeable phenotype, possible due to the posttranslational regulation of the protein (Blanco et al. 2009). In this work, we generated transgenic roots that constitutively express mutated forms of RabA2 with single point substitutions in amino acids that are known to participate in the hydrolysis of GTP and the GDP/GTP exchange. Both mutations affected root hair growth, as well as progression and integrity of ITs. As a consequence of this aberrant infection, nodule development was impaired. Translational fusion to fluorescence proteins revealed that wild type RabA2, but not its mutated forms, localized to Golgi mobile vesicles associated to the plasma membrane and surrounding the growing IT in epidermal cells. Together, these results suggest that RabA2 is a shared component of molecular mechanisms that govern polar growth and is required to maintain the integrity of the IT. 


\section{Materials and methods}

\section{Plant growth, transformation and inoculation with $R$. etli}

The Rhizobium etli strains SC15, as well as CFNX5 expressing the fluorescent protein DsRed, were previously reported (Aguilar et al. 2004; Battaglia et al. 2014). Composite plants of common bean (Phaseolus vulgaris) accession NAG12 were obtained by transformation with Agrobacterium rhizogenes strain K599, as previously reported (Bond and Gresshoff 1993; Blanco et al. 2009). Roots were transformed with the control p35S:GFPGUS+ (GFP GUS), p35S:FLAG-RabA2 ${ }^{\mathrm{wt}}, \quad$ p35S:FLAG-RabA2 ${ }^{\mathrm{Q} 64 \mathrm{~L}}$ or p35S:FLAG-RabA2 ${ }^{\mathrm{S} 26 \mathrm{~N}}$. Plants were grown in MLR$350 \mathrm{HT}$ growth chambers (Sanyo Electric) at $28^{\circ} \mathrm{C}$ with day/night cycles of $16 \mathrm{~h} / 8 \mathrm{~h}$ and $80 \%$ humidity. Transgenic roots were inoculated with $R$. etli strains 5 days after transplantation to acrylic boxes (Peltzer Meschini et al. 2008).

\section{Site directed mutagenesis}

Mutations were introduced in the RabA2 open reading frame cloned in the pTOPO-TA vector. The Gene Tailor Site-Directed Mutagenesis kit (INVITROGEN, Carlsbad, CA) and the specific primers described in Supplementary Table 1 (RabA2 Q64L F mutagenesis, RabA2 S26N $\mathrm{F}$ mutagenesis and RABA2 $\mathrm{R}$ mutagenesis) were used according to manufacturer's recommendations.

\section{Cloning}

Vector constructs for plant transformation were obtained using Gateway technology (INVITROGEN) and confirmed by sequencing. For overexpression constructs, the open reading frame of RabA2 ${ }^{\mathrm{wt}}, \mathrm{RabA} 2^{\mathrm{Q} 64 \mathrm{~L}}$ and $\mathrm{RabA} 2^{\mathrm{S} 26 \mathrm{~N}}$ were amplified by PCR using RabA2 OE F and RabA2 OE R (Supplementary Table 1), cloned into the pENTR/D-TOPO vector and recombined into the destination vector $\mathrm{p} 35 \mathrm{~S}: \mathrm{HF}-$ GATA (Mustroph et al. 2009). For subcellular localization, translational fusions of RabA2 ${ }^{\mathrm{wt}}, \mathrm{RabA}^{\mathrm{Q} 64 \mathrm{~L}}$ and $\mathrm{RabA2}{ }^{\mathrm{S} 26 \mathrm{~N}}$ to the C-terminal end of GFP under the control of $\mathrm{p} 35 \mathrm{~S}$ were generated by recombination of pENTR/D-TOPO vectors with pMDC43 (Curtis and Grossniklaus 2003; Blanco et al. 2009). The p35S:GFP vector was used as a control of free GFP signal, which was distributed in the nucleus and the cytoplasm of root hairs.

\section{Infection thread and polar growth phenotypic analysis}

Bright-field and epifluorescence imaging were used for root hair and infection thread phenotypic analysis with an Olympus IX51 inverted microscope (OLYMPUS
CORPORATION, Center Valley, PA). Root hair length and density were analyzed as described by Blanco et al. 2009, using plants grown in agar-Fahraeus acrylic boxes. Root hair deformation and IT formation were measured in lateral hairy roots of $1 \mathrm{~cm}$ of length in composite plants at $48 \mathrm{~h}$ after infection (HAI) and 10 days after infection (DAI) with $R$. etli CFNX5 expressing DsRed, respectively.

\section{Nodule phenotypic analysis}

The nodule phenotypic analysis was performed in several transgenic roots of at least ten composite plants. Three completely independent experiments were carried out at different times. The number of nodules per root developed in composite plants expressing each construct was recorded during the first 25 DAI with the SC15 R. etli strains. Nodule diameter was measured at 18 DAI with $R$. etli SC15 strain. Dry weight was measured as previously described by Zanetti et al. 2010 using at least eight plants per construct. Statistical significance analysis was performed by unpaired two-tailed Student $t$ tests.

\section{Immunoblot analysis}

Proteins were extracted from root tissue of individual composite plants with sample buffer $3 \times$ and separated by $12 \%$ SDS-PAGE (Sambrook and Russel 2001). After transfer to nitrocellulose membranes, the blots were incubated with anti-FLAG horseradish peroxidase (HRP)-conjugated monoclonal antibody (1:500; Sigma-Aldrich) as previously described (Zanetti et al. 2010) for detection of FLAGRabA2 proteins or with an anti-GFP JL-8 polyclonal antibody (1:2500, BD living color) and a goat anti-rabbit conjugated to HRP as secondary antibody (1:3000, BIORAD, Hercules, CA) for detection of the GFP-RabA2 fusion.

\section{Quantitative RT-PCR assays}

Total RNA extraction from composite plant roots, cDNA synthesis and reverse transcription followed by quantitative PCR (RT-qPCR) analysis were performed as described (Peltzer Meschini et al. 2008). For quantitative measurements of endogenous RabA2 transcripts, a forward primer that binds to the coding region of RabA2 (qRabA2 F) and a primer that binds to the $3^{\prime}$ untranslated (UTR) region (qRabA2 R) were used, whereas for measurement of the transgenic RabA2 transcripts, a combination of RabA2 F and a primer that binds to the $3^{\prime} \mathrm{UTR}$ of the ocs gene (OCS 3' R) was used. All primers used in RT-qPCR experiments are listed in the Supplementary Table 1. A PCR reaction using RNA as template before cDNA synthesis was performed to verify the absence of genomic DNA contamination. The transcript level of each analyzed gene was 
normalized with the relative transcript level of the reference gene Elongation factor $1 \alpha(E F 1 \alpha)$. At least two biological replicates were performed per condition.

\section{Subcellular localization}

For localization analyses, p35S:GFP-RabA2 ${ }^{\mathrm{wt}}$, p35S:GFPRabA2 ${ }^{\text {Q64L }}$, p35S:GFP-RabA2 ${ }^{\text {S26N }}$ or p35S:GFP were used (Blanco et al. 2009). One of the ArfA1 genes from Medicago truncatula (Medtr1g086480) was amplified using the primers ArfA1f and ArfA1r (Supplementary Table 1). The amplified fragment was cloned in pENTR/D-TOPO and recombined in pK7RWG2 to express ArfA1 fused to RFP in the $C$ terminus (ArfA1-RFP). Sequencing of the entry construct verified that the fragment corresponds to the ArfA1e gene. The molecular markers G-rk CD3-967 and ER-rk CD3-959 were used to label the Golgi apparatus (G-rk CD3-967 is based on the cytoplasmic tail and transmembrane domain of the soybean $\alpha$-1,2-mannodidase I fused to mCherry) and the endoplasmic reticulum (ERrk CD3-959 encodes a chimeric protein containing the signal peptide of the wall-associated kinase 2 and the ER retention signal at the $\mathrm{N}$ and $\mathrm{C}$ termini of the mCherry protein, respectively) (Nelson et al. 2007). The pCMULE marker of late endosome is a fusion between mCherry and MtRAB5A2 (Ivanov and Harrison 2014). All these constructs were introduced in Agrobacterium tumefaciens CV3101 and used to agroinfiltrate Nicotiana benthamiana leaves as previously described (Battaglia et al. 2014).

\section{Microscopic observations}

Nodule tissue was processed as described in Zanetti et al. 2010. Sections of $1-2 \mu \mathrm{m}$ were stained with $0.04 \%$ toluidine blue and examined with an Olympus IX51 inverted microscope (OLYMPUS CORPORATION). Ultrathin sections of $70 \mathrm{~nm}$ were stained with uranyl acetate and lead citrate, and analyzed with a JEM 1200 EX II (JEOL, Tokio, Japan) transmission electron microscope. Confocal microscopy for subcellular localization analysis and observation of ITs were performed on $N$. benthamiana leaves or root segments of wild type and transgenic roots of common bean with an inverted SP5 microscope (LEICA MICROSYSTEMS, Wetzlar, Germany) using a $\times 20$ or a $\times 63$ objective (numerical aperture of 0.5 ). GFP, RFP, mCherry and DsRed were excited using $488 \mathrm{~nm}$ (GFP) and $543 \mathrm{~nm}$ (RFP, mCherry and DsRed) lasers and emissions were collected between 500 and $550 \mathrm{~nm}$ (GFP), 600-660 nm (RFP), 584-660 nm (mCherry) and 578-626 nm (DsRed). Images were processed with the LAS Image Analysis software (LEICA MICROSYSTEMS).

\section{Results}

\section{Composite plants expressing RabA2 ${ }^{\mathrm{Q} 64 \mathrm{~L}}$ or $\operatorname{RabA2} 2^{\mathrm{S} 26 \mathrm{~N}}$ are affected in root hair growth and deformation in response to rhizobia}

In order to evaluate the role of RabA2 during IT formation, GTP-locked and GDP-bound mutant variants of RabA2 were generated by directed mutagenesis in specific amino acid residues that affect either the hydrolysis of GTP $\left(\mathrm{RabA2} 2^{\mathrm{Q} 64 \mathrm{~L}}\right)$ or the ability to exchange GDP by GTP $\left(\right.$ RabA2 $^{\text {S26N)}}$ ) (Zheng et al. 2005; Chow et al. 2008). These RabA2 versions were expressed in common bean roots as translational fusions to the FLAG epitope under the control of the CaMV35S promoter (Supplementary Fig. S1a). This promoter is active in roots and at different stages of nodule development in common bean (Estrada-Navarrete et al. 2006, 2007). Composite plants, whose roots are transgenic and the aerial tissue is wild type, were obtained by Agrobacterium rhizogenes mediated transformation. In our hands, this transformation method produced a high proportion of transgenic roots (90-95\%) in Mesoamerican accessions (Rípodas et al. 2013; Battaglia et al. 2014) as revealed by the use of the GFP fluorescent marker, which is consistent with the transformation efficiencies previously reported by Estrada-Navarrete et al. (2006). Reverse transcription followed by quantitative PCR (RT-qPCR) using a primer combination designed to specifically detect the mRNA transcribed from the transgene and immunoblot analyses using antiFLAG antibodies confirmed the expression of RabA2 mutated forms in transgenic roots. On the other hand, a combination of primers that specifically detect the mRNA produced from the endogenous RabA2 gene revealed that expression of the FLAG-RabA2 mutated forms did not affect the transcript levels of the endogenous RabA2 gene (Supplementary Fig. S1b-d).

Considering that the post-transcriptional silencing of RabA2 by RNAi produced severe defects in polar growth of the root hair, we questioned whether expression of the mutated forms of this protein also affected root hair formation and elongation, as well as the curling of root hairs in response to rhizobia inoculation. Roots expressing $\mathrm{RabA2} 2^{\mathrm{Q} 64 \mathrm{~L}}$ and $\mathrm{RabA2} 2^{\mathrm{S} 26 \mathrm{~N}}$ exhibited shorter root hairs, with reductions of 27 and 23\% in root hair length, respectively, as compared with control roots expressing GFP GUS (Fig. 1a). In addition, root hair density was reduced by $29 \%$ in $\mathrm{RabA2} 2^{\mathrm{S} 26 \mathrm{~N}}$, whereas no significant effect was detected in hairy roots expressing the GTPlocked RabA2 ${ }^{\text {Q64L }}$ variant (Fig. 1b). Attachment of rhizobia to the root hair surface produces a change in the direction of polar growth, forming a characteristic curl in the tip of the actively growing root hair. This curl entraps the bacteria colony between two layers of cell 

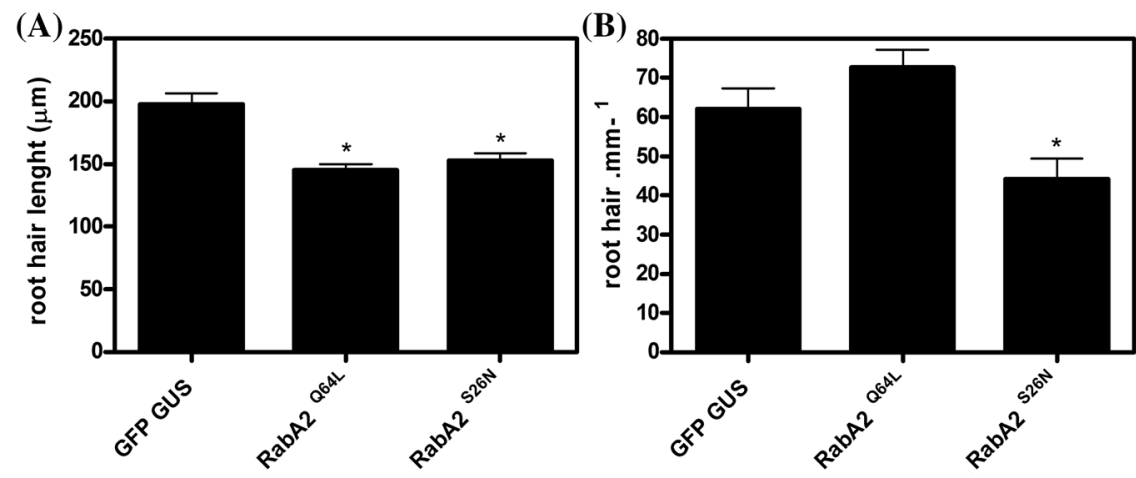

(D)

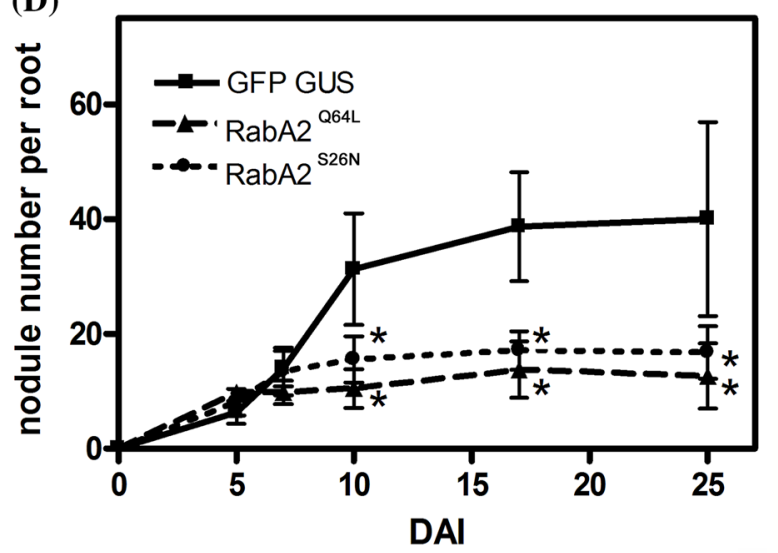

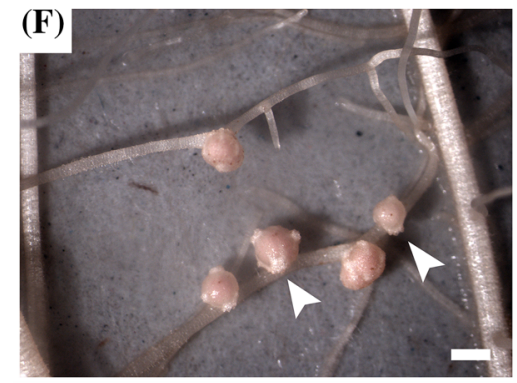

GFP GUS

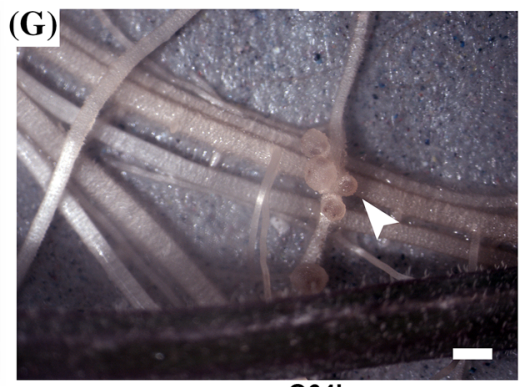

RabA2

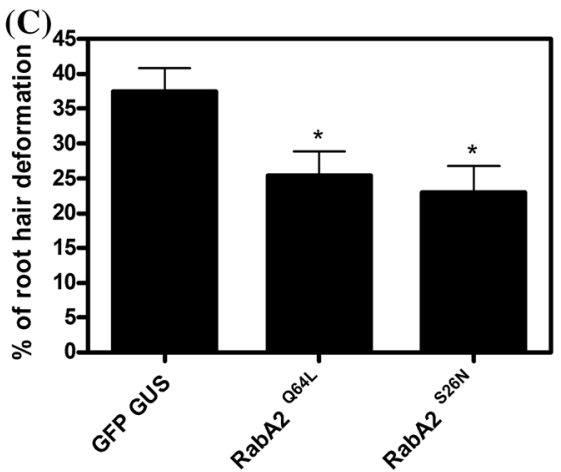

(E)
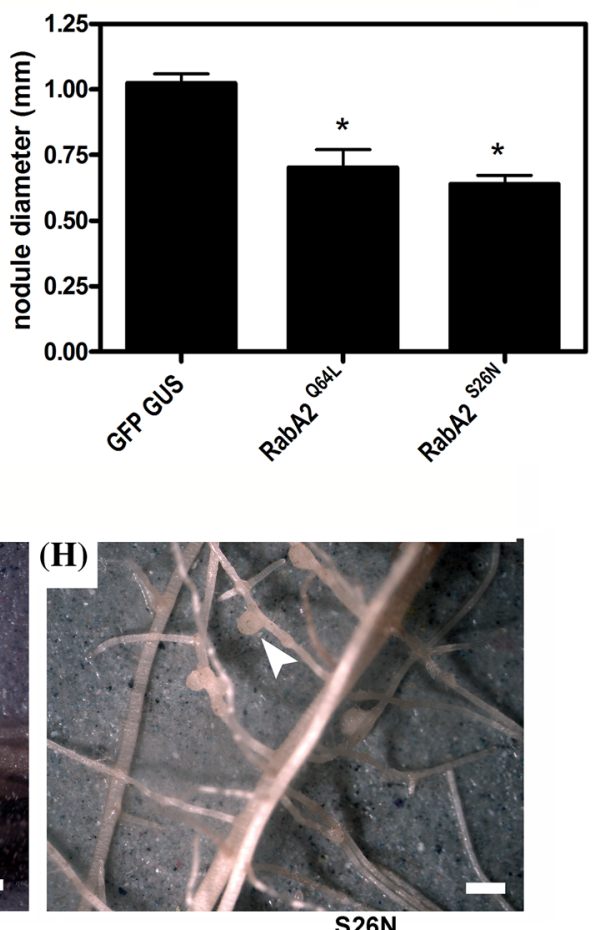

RabA2
Fig. 1 Expression of RabA2 $2^{\mathrm{Q} 64 \mathrm{~L}}$ and $\mathrm{RabA2} 2^{\mathrm{S} 26 \mathrm{~N}}$ affects root hair growth and nodulation. Length (a), density (b) and deformation of root hairs in response to rhizobia (c) were measured on GFP GUS, $\mathrm{RabA2}^{\mathrm{Q} 64 \mathrm{~L}}$ and $\mathrm{RabA2} 2^{\mathrm{S} 26 \mathrm{~N}}$ roots. Measurements were taken on at least ten independent transgenic roots from eight GFP GUS, RabA2 ${ }^{\mathrm{Q} 64 \mathrm{~L}}$ or RabA2 ${ }^{\mathrm{S} 26 \mathrm{~N}}$ composite plants. Deformation was determined as the percentage of root hairs that presented a curled tip 48 HAI with $R$. etli. Bars represent the mean and SE of three biological replicates ( $\mathrm{n} \geq 20$ for each condition analyzed). Asterisks indicate statistical significance according to Student $t$ test with $\mathrm{P}<0.05$. More than 200 root hairs per construct were used for each measurement. The average number of nodules per root was scored between 0 and 25 DAI with $R$. etli strain SC15 on more than 10 independent transgenic

wall, a step required for initiation of the IT (Catoira et al. 2001). Measurement of root hair deformation $48 \mathrm{~h}$ after inoculation (HAI) with Rhizobium etli in RabA2 ${ }^{\mathrm{Q} 64 \mathrm{~L}}$ or RabA2 ${ }^{\mathrm{S} 26 \mathrm{~N}}$ hairy roots revealed a significant reduction of 29.5 and $38.7 \%$, respectively, as compared with GFP roots from at least seven composite plants for each condition analyzed (d). Error bars represent SE of two biological replicates with $\mathrm{n} \geq 70$. Asterisks indicate differences between RAbA2 $2^{\mathrm{Q} 64 \mathrm{~L}}$ or $\mathrm{RabA}_{2}{ }^{\mathrm{S} 26 \mathrm{~N}}$ and GFP GUS roots that were statistically significant (Student $t$ test $\mathrm{P}<0.05$ ). The nodule diameter was measured at $18 \mathrm{DAI}$ with $R$. etli in transgenic roots from GFP GUS, RAbA2 ${ }^{\mathrm{Q} 64 \mathrm{~L}}$ and or RabA2 ${ }^{\mathrm{S} 26 \mathrm{~N}}$ composite plants (e). Bars represent the mean and SE of three biological replicates, $\mathrm{n} \geq 30$ for each condition tested. Asterisks indicate statistical significance (Student $t$ test $\mathrm{P}<0.05$ ). $\mathbf{f}-\mathbf{h}$ Pictures of nodules developed at 18 DAI with $R$. etli in transgenic roots from GFP GUS (f), RabA2 ${ }^{\mathrm{Q} 64 \mathrm{~L}}(\mathbf{g})$ or RabA2 $2^{\mathrm{S} 26 \mathrm{~N}}(\mathbf{h})$. Arrowheads point to the nodules. Note that lenticels were present only in nodules of GFP GUS composite plants. Bars $1 \mathrm{~mm}$

GUS control plants (Fig. 1c). These results reinforce the importance of RabA2 in root hair polar growth and preinfection steps of root nodule symbiosis. 


\section{Expression of RabA2 ${ }^{\mathrm{Q} 64 \mathrm{~L}}$ and $\operatorname{RabA2}^{\mathrm{S26N}}$ impairs nodulation}

In order to investigate the effect of the expression of the mutated forms of RabA2 in the development of nitrogen fixing nodules, we performed a time-course nodulation analysis on composite plants that express RabA2 ${ }^{\mathrm{Q} 64 \mathrm{~L}}$, RabA2 ${ }^{\mathrm{S} 26 \mathrm{~N}}$ or GFP GUS. At 10 days after inoculation (DAI) with $R$. etli strain $\mathrm{SC} 15$, RabA2 ${ }^{\mathrm{Q} 64 \mathrm{~L}}$ and $\mathrm{RabA} 2^{\mathrm{S} 26 \mathrm{~N}}$ roots presented a significant reduction of approximately 70 and $50 \%$ in the number of nodules, respectively, as compared to GFP GUS roots, and these differences were maintained at later time points (Fig. 1d). Nodules formed in both RabA2 $2^{\mathrm{Q} 64 \mathrm{~L}}$ and RabA2 ${ }^{\mathrm{S} 26 \mathrm{~N}}$ roots were significantly smaller than those developed in GFP GUS control roots (Fig. 1e-h). The majority of these small nodules was pale and without lenticels, whereas those developed in control roots presented the pink color characteristic of mature nodules that express leghemoglobin (Fig. 1f-h). These phenotypic observations suggest that nitrogen fixation can be compromised in nodules formed in roots expressing the mutant versions of RabA2. This is further supported by the lower dry weight of shoots in RabA2 ${ }^{\mathrm{Q} 64 \mathrm{~L}}$ and $\mathrm{RabA2} 2^{\mathrm{S} 26 \mathrm{~N}}$ as compared with that of GUS GFP composite plants (Supplementary Fig. S2).
Small nodules formed in roots expressing the mutated variants of RabA2 were partially infected. Whereas most cells of the central tissue were infected with rhizobia in control GFP GUS nodules, only few cells were occupied by rhizobia in RabA2 ${ }^{\mathrm{Q} 64 \mathrm{~L}}$ nodules (Fig. 2a, b). On the other hand, the central tissue of RabA2 ${ }^{\mathrm{S} 26 \mathrm{~N}}$ nodules contained a high proportion of cells that presented irregular shape and, although many of these cells were infected, they were not fully occupied with symbiosomes (Fig. 2c and Supplementary Fig. S3). To evaluate whether the symbiosomes formed in RabA2 ${ }^{\mathrm{Q} 64 \mathrm{~L}}$ and $\mathrm{RabA2} 2^{\mathrm{S} 26 \mathrm{~N}}$ contained fully differentiated bacteroids, transmission electron microscopy of ultrathin nodule section was performed. Symbiosomes formed in GFP GUS control plants were normal, containing one or more bacteroids surrounded by an intact symbiosome membrane and embedded in a dense cytoplasm (Fig. 2d), as previously reported by Cermola et al. (2000). In contrast, nodules formed in $\mathrm{RabA2} 2^{\mathrm{Q} 64 \mathrm{~L}}$ and $\mathrm{RabA} 2^{\mathrm{S} 26 \mathrm{~N}}$ roots presented signs of disintegrated and/or merged symbiosome membranes and bacteria released in the cytoplasm (Fig. 2e, f). Symbiosome membrane disintegration and merging was previously observed in old senescent nodules as well as in young nodules formed by ineffective strains of $R$. etli (Cermola et al. 2000). Our observations suggest that miss-regulation of RabA2 produces defects in the formation of the symbiosome membrane or that the partially

\section{GFP GUS}
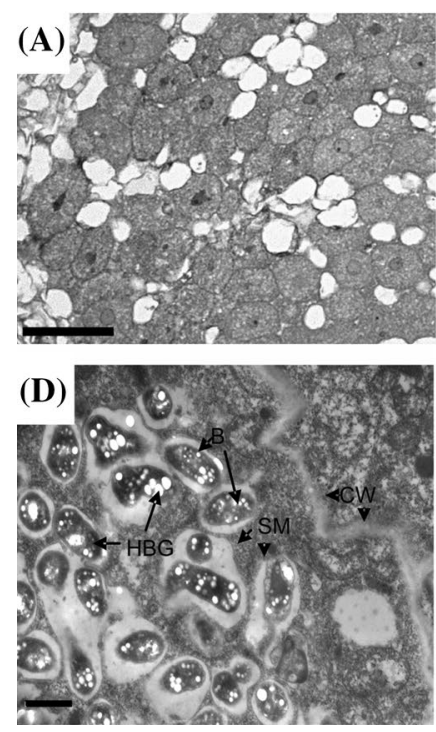

RabA2
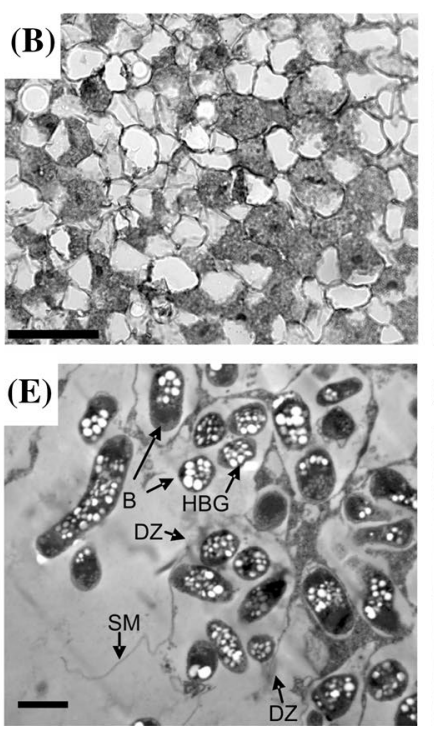

RabA2
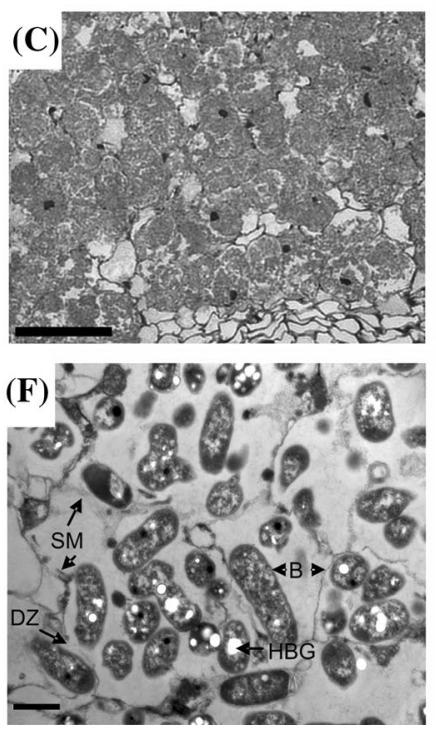

\section{OPTICAL}

TEM
Fig. 2 Cytological characterization of $\mathrm{RabA2}^{\mathrm{Q} 64 \mathrm{~L}}$ and $\mathrm{RabA2} 2^{\mathrm{S} 26 \mathrm{~N}}$ nodule sections. a-c Light micrographs of semi-thin sections of the central tissue of nodules formed in GFP GUS (a), RabA2 ${ }^{\mathrm{Q} 64 \mathrm{~L}}(\mathbf{b})$, and $\mathrm{RabA} 2^{\mathrm{S} 26 \mathrm{~N}}$ (c) composite plants at 21 DAI with $R$. etli. Sections were stained with $0.04 \%$ toluidine blue. Bars $50 \mu \mathrm{m}$. d-f Transmission electron microscopy of ultrathin sections of GFP GUS (d),
RabA2 $2^{\mathrm{Q} 64 \mathrm{~L}}$ (e) and RabA2 ${ }^{\mathrm{S} 26 \mathrm{~N}}$ (f) nodules at 21 DAI with rhizobia. $C W$ cell wall, $B$ bacteroids, $S M$ symbiosome membrane, $D Z$ disintegration zone, $H B G$ poly- $\beta$-hydroxy butyrate granules. Note the disintegrated membrane of the symbiosome pointed by the arrow labeled as SM in e. $\mathbf{d}-\mathbf{f}$ Bars $=1 \mu \mathrm{m}$ 
infected nodules observed in RabA2 $2^{\mathrm{Q} 64 \mathrm{~L}}$ and $\mathrm{RabA} 2^{\mathrm{S} 26 \mathrm{~N}}$ roots are senescing earlier than the control ones.

\section{$\operatorname{RabA2} 2^{\mathrm{Q} 64 \mathrm{~L}}$ and $\mathrm{RabA2} 2^{\mathrm{S26N}}$ expressing roots are affected in IT progression and maintenance of IT integrity}

IT progression initiates from the infection chamber by a switch from radial to polar growth (Fournier et al. 2015). Considering the function of monomeric GTPases in vesicle trafficking associated to cell wall and plasma membrane remodeling, we hypothesized that alterations on RabA2 regulation might affect IT formation or elongation. To visualize the progression of the infection events, we used a $R$. etli strain that constitutively expresses the fluorescent protein DsRed. The density of ITs observed at 5 DAI was not significantly different between RabA2 ${ }^{\mathrm{Q} 64 \mathrm{~L}}, \mathrm{RabA}^{\mathrm{S} 26 \mathrm{~N}}$ and control GFP GUS roots; however, a $20 \%$ reduction in IT density was observed in RabA2 ${ }^{\mathrm{Q} 64 \mathrm{~L}}$ roots (Fig. 3a). In order to assess the IT progression towards cortical cells, we quantified and classified ITs as elongated ITs ending in the root hair, ending in the epidermal cell layer (in the same epidermal cell producing the root hair or adjacent cells of the epidermis) or reaching the cortex and releasing bacteria within the dividing cortical cells, as previously described by Zanetti et al. (2010) and illustrated in Fig. 3c. Mutations of RabA2 impaired IT progression, since only 27 and $33 \%$ of the ITs formed on RabA2 $2^{\mathrm{Q} 64 \mathrm{~L}}$ and RabA2 $2^{\mathrm{S} 26 \mathrm{~N}}$ roots reached the cortex, respectively, a statistically significant difference (Student $t$ test $\mathrm{P}<0.05$ ) compared with the $61 \%$ of these infection events recorded in control GFP GUS roots (Fig. 3b). This result indicates that progression of the infection toward the dividing cells in the cortex is severely compromised by the expression of RabA2 mutated forms. Interestingly, some ITs showed premature release of bacteria (burst) into the cytoplasm of the root hair cells (Fig. 4). These abnormal ITs were observed only in roots expressing the mutant forms of RabA2, and not in the GUS GFP roots (Table 1). Abnormal ITs represented 15 and $18 \%$ of the total recorded ITs $(n>50)$ in RabA2 $2^{\text {Q64L }}$ and RabA2 ${ }^{\mathrm{S} 26 \mathrm{~N}}$ roots, respectively. In these abnormal infection events, the bacteria were released into the epidermal infected cells (Fig. 4a-e), a phenotype that was already observed in legume mutants with defects in rhizobial infection (Yokota et al. 2009; Qiu et al. 2015). Occasionally, some of these abnormal infection events that had released bacteria in the root hair cell were able to extend toward epidermal cells adjacent to the root hair (Fig. 4f) or progressed and released the bacteria in the nodule primordia (Fig. $4 \mathrm{~g}$ ).

\section{RabA2 colocalizes in Golgi vesicles with ArfA1}

We have previously shown that common bean RabA2 localizes in mobile vesicles that travels around the membrane in root hairs (Blanco et al. 2009). In order to establish the identity of these vesicles, we used a series of molecular markers associated to subcellular compartments of the secretory pathway, which were transiently coexpressed with GFP-RabA2 in Nicotiana benthamiana leaf epidermal cells by agroinfiltration. We observed partial colocalization between GFP-RabA2 and markers of Golgi and late endosome (Fig. 5, Supplementary Video 1). In contrast, the marker of endoplasmic reticulum labeled a different group of vesicles that RabA2. ArfA1, a monomeric GTPase of the Arf family, has been studied in different organisms and its localization in Golgi and trans-Golgi vesicles has been amply documented (Pimpl et al. 2000; Takeuchi et al. 2002; $\mathrm{Xu}$ and Scheres 2005; Stefano et al. 2006; Robinson et al. 2011). We observed localization of both GTPases in mobile
(A)

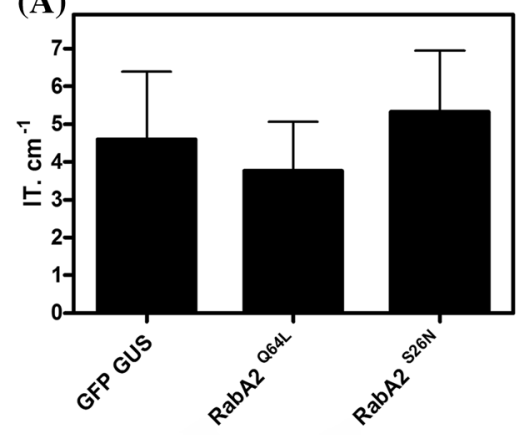

(B)

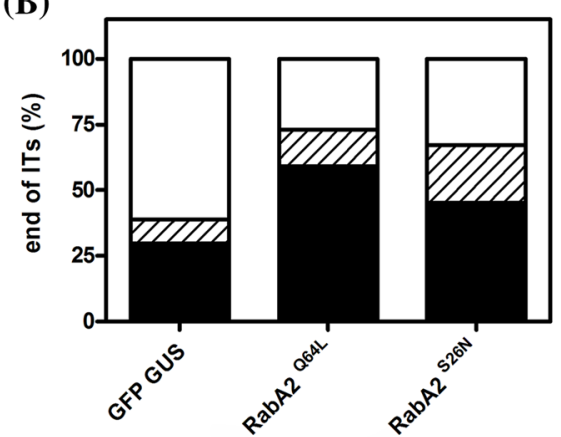

(C)
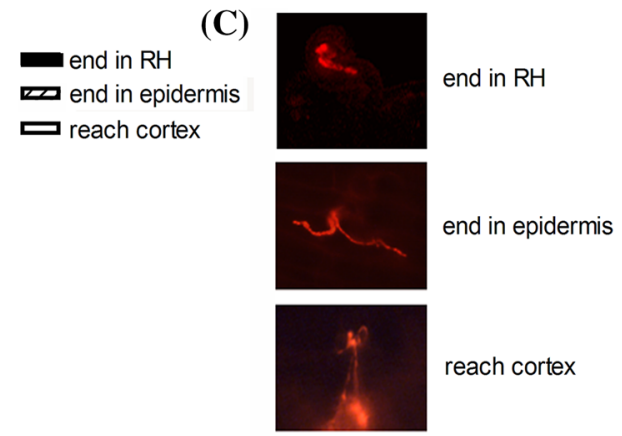

Fig. 3 Expression of RabA2 $2^{\mathrm{Q} 64 \mathrm{~L}}$ and $\mathrm{RabA} 2^{\mathrm{S} 26 \mathrm{~N}}$ affects progression of ITs. a The number of ITs per $\mathrm{cm}$ of root developed at 7 DAI was quantified using a strain of $R$. etli expressing DsRed in at least ten independent composite plants. Bars represent the mean and the SE of two biological replicates ( $\mathrm{n} \geq 35$ for each condition). b Percentage of ITs that ended in the root hair (RH), the epidermis or reached the cortex. More than 150 ITs were recorded in at least ten independent roots. $\mathbf{c}$ Fluorescence microscopy images representing the different IT categories: end in root hair $(\mathrm{RH})$ when the IT does not reach the body of the trichoblast (superior panel), end in epidermis as the ITs that growth toward the interior of the cell to reach the body of the trichoblast that originated the infected $\mathrm{RH}$ or expand to adjacent cells in the epidermis (middle panel) and reach cortex as the normal expanded infection events (inferior panel) 

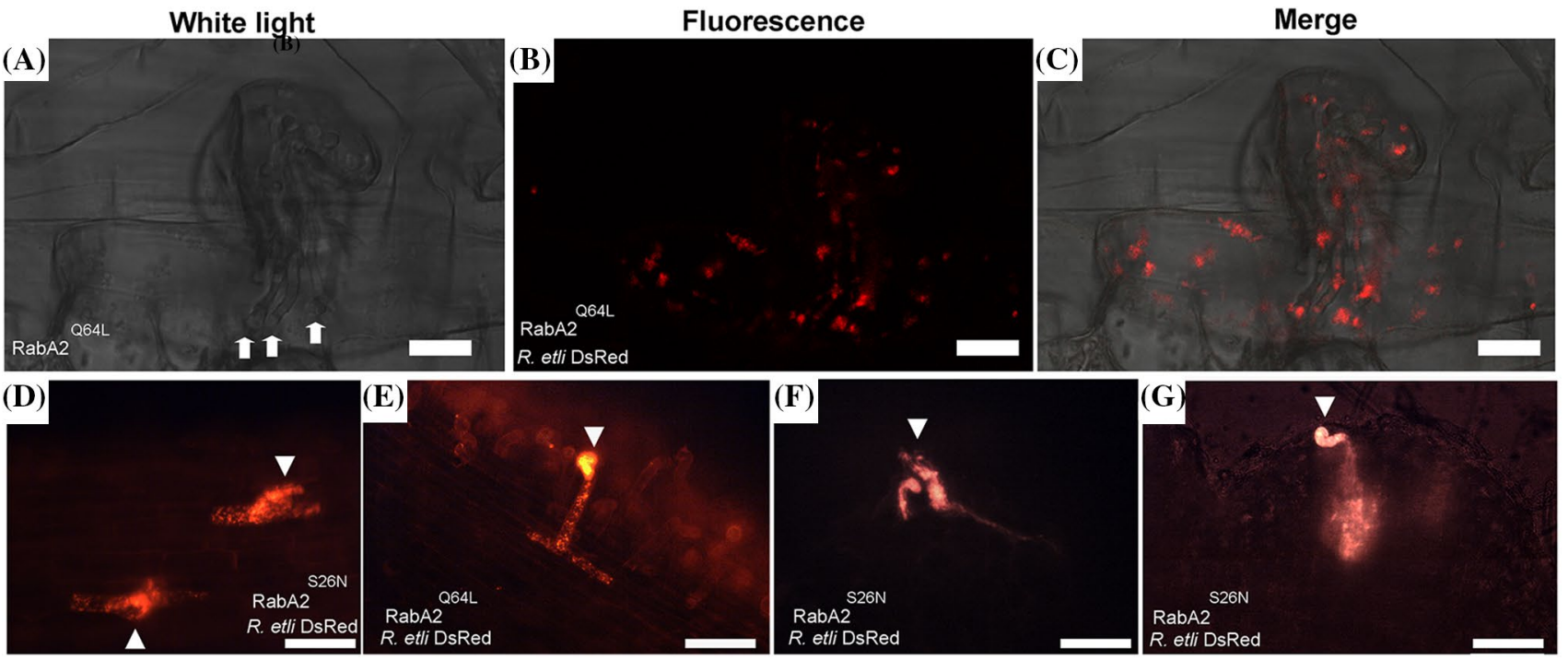

Fig. 4 Abnormalities of IT formation in RabA2 ${ }^{\mathrm{Q} 64 \mathrm{~L}}$ and RabA2 ${ }^{\mathrm{S} 26 \mathrm{~N}}$ roots. a-c Abnormal IT formed in a RabA2 ${ }^{\mathrm{Q} 64 \mathrm{~L}}$ root showing fluorescent rhizobia in the cytoplasm of a root hair at 7 DAI with a strain of $R$. etli expressing DsRed. Images obtained under white light (a), fluorescence (b) or merged (c) are shown. Arrows point to the tips of a

Table 1 Expression of RabA2 $2^{\mathrm{Q} 64 \mathrm{~L}}$ and RabA2 $2^{\mathrm{S} 26 \mathrm{~N}}$ generates abnormal ITs

\begin{tabular}{lcll}
\hline & Root hair & Epidermis & $\begin{array}{l}\text { Dividing cortex/ } \\
\text { nodule primor- } \\
\text { dia }\end{array}$ \\
\hline $\begin{array}{l}\text { Aberrant ITsX100/Total ITs } \\
\text { GFP GUS }\end{array}$ & 0 & 0 & \\
RabA2 & & \\
RabA2 & 10 & 1 & 0 \\
S26N & 14 & 2 & 4 \\
\hline
\end{tabular}

${ }^{\text {a } I T s ~ w e r e ~ c l a s s i f i e d ~} 5$ DAI with a $R$. etli strain expressing DsRED $(\mathrm{n}>50)$

vesicles and, to certain extent, in the plasma membrane and the cytoplasm, as expected considering the regulatory cycle of GTPases (Fig. 5, Supplementary Video 2). The strong colocalization observed between these two proteins suggests that RabA2 might be associated to the membrane of vesicles that form the Golgi stack and the trans-Golgi network.

\section{Miss-regulation of RabA2 activity affects the subcellular localization of RabA2}

In order to analyze RabA2 subcellular localization during IT progression and whether mutations in RabA2 affected that localization, we generated composite plants expressing GFP-RabA2 ${ }^{\text {wt }}$, GFP-RabA2 ${ }^{\mathrm{Q} 64 \mathrm{~L}}$ or GFP-RabA2 ${ }^{\mathrm{S} 26 \mathrm{~N}}$ translational fusion proteins and inoculated them with the $R$. etli strain expressing DsRed. As shown in Fig. 6, ramified IT. Bars $10 \mu \mathrm{m}$. d-g Examples of ITs with rhizobia released into the cytoplasm of root hairs. Most of these infections aborted in the root hair (d, e), but some progressed to the epidermis (f) or reached cortical cells (g). Arrowheads indicate root hairs with bacteria released in the cytoplasm. Bars $50 \mu \mathrm{m}$

GFP-RabA2 ${ }^{\text {WT }}$ localized in moving vesicles near the root hair membrane and around the IT, surrounding the signal of fluorescent bacteria (Fig. 6a-c and Supplementary Video 3 ). GFP-labeled vesicles were also detected around the nucleus and in cytoplasmic bridges connecting the plasma and the IT membranes (Supplementary Fig. S4). These punctate structures were not observed when the mutant variants of RabA2 were expressed (Fig. 6d-i and Supplementary Video 4). Instead, the fluorescence signal in the GFP-RabA2 ${ }^{\mathrm{Q} 64 \mathrm{~L}}$ or GFP-RabA2 ${ }^{\mathrm{S} 26 \mathrm{~N}}$ transgenic roots was dispersed in the root hair cell, consistent with a cytoplasmic localization (Fig. $6 \mathrm{~d}, \mathrm{~g}$ ). Infections produced in roots expressing GFP-RabA2 ${ }^{\mathrm{Q} 64 \mathrm{~L}}$ or GFP-RabA2 ${ }^{\mathrm{S} 26 \mathrm{~N}}$ showed the same defects in IT progression observed in RabA2 ${ }^{\mathrm{Q} 64 \mathrm{~L}}$ and $\mathrm{RabA} 2^{\mathrm{S} 26 \mathrm{~N}}$ roots, indicating that the presence of the fluorescent protein did not affect the negative effect produced by the expression of the mutated variants of RabA2. These results indicate that miss-regulation of RabA2 activity affects its subcelullar localization during IT progression and is consistent with the established role of Rab proteins in membrane trafficking associated to polar growth.

\section{Discussion}

This work shows a connection between a monomeric GTPase that is involved in vesicle trafficking and the progression and maintenance of the integrity of ITs, a key step on the establishment of nitrogen-fixing symbiosis. RabA2 was previously implicated in the polar growth of root hairs 


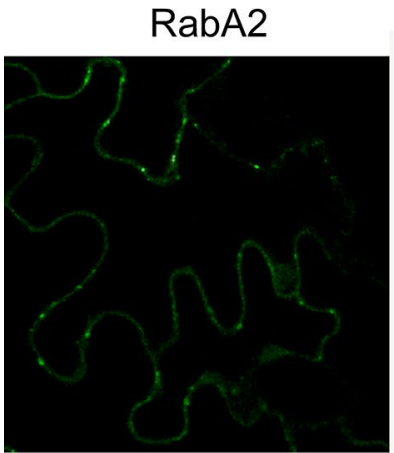

$\operatorname{RabA2}$

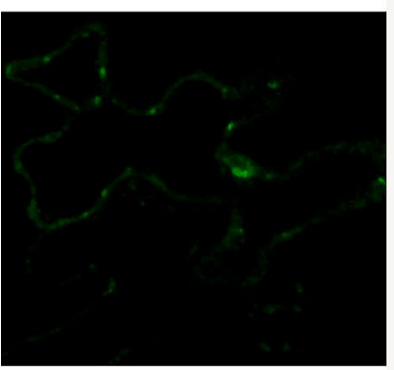

$\operatorname{RabA2}$

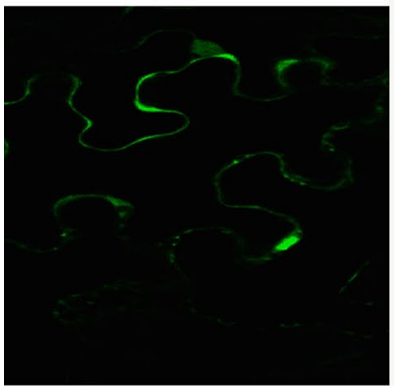

$\operatorname{RabA2}$

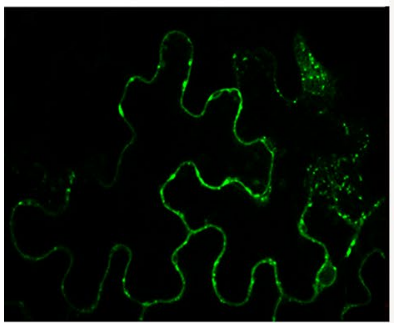

ER

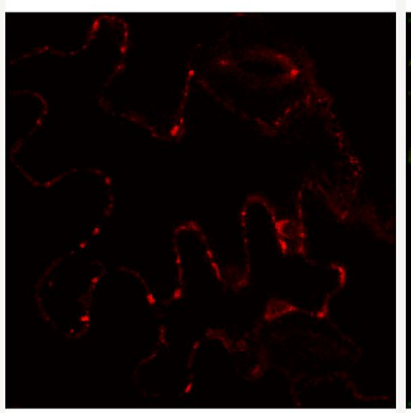

ArfA1

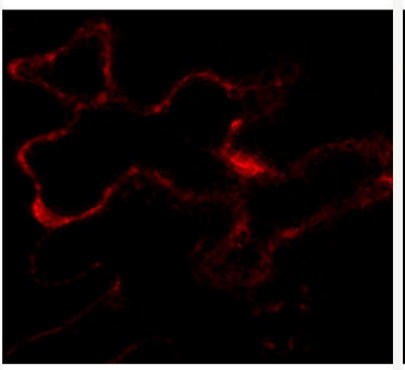

LE

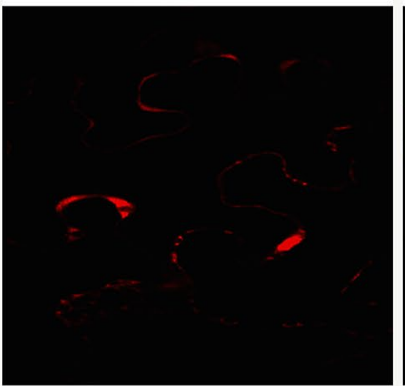

Golgi

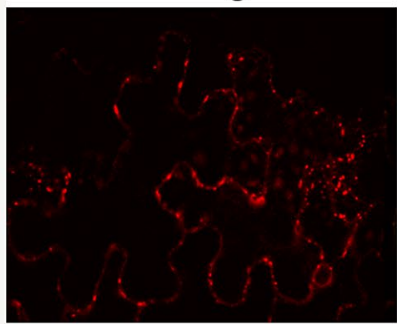

Overlay

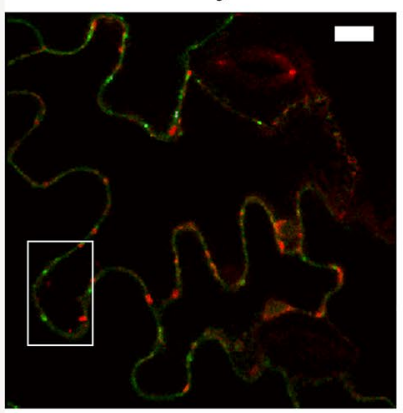

Overlay

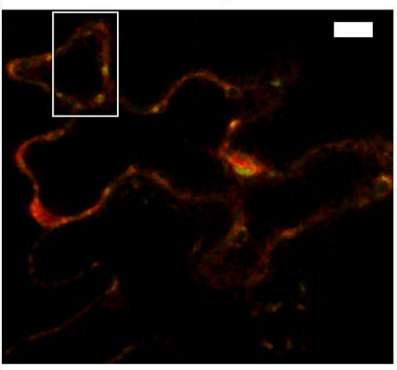

Overlay
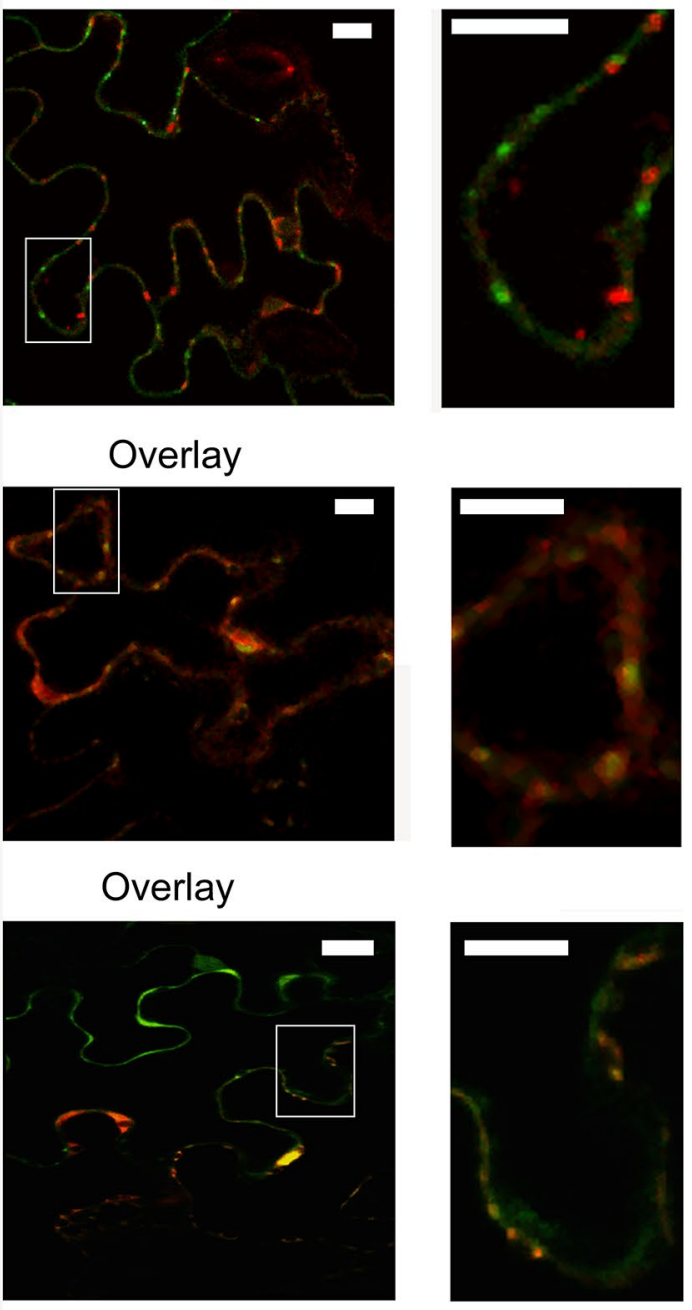

\section{Overlay}
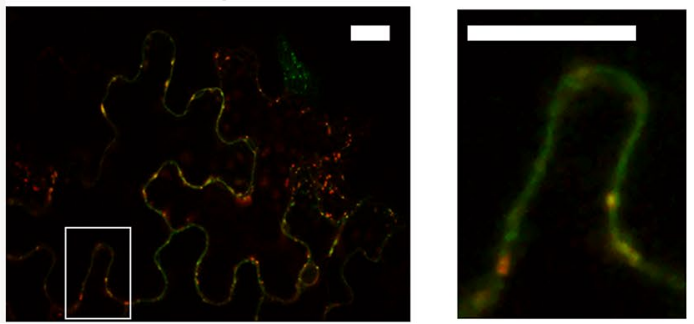

Fig. 5 RabA2 colocalizes with ArfA1 at Golgi/trans-Golgi stacks. Subcellular localization of GFP-RabA2 and molecular markers of endoplasmic reticulum (ER), ArfA1 (Golgi and trans-Golgi), late endosome (LE) and Golgi stacks in epidermal cells of N. benthami-

and the curling that entrap bacteria at a pre-infection stage of the symbiosis (Blanco et al. 2009). Taken together, the results presented here suggest that the molecular machinery that is part of the IT formation and elongation during symbiosis is the same that participates of polar growth processes, such as root hair or pollen tube elongation. Proposed roles for vesicle transport in IT formation are related ana. GFP, RFP and Cherry fluorescence was visualized by confocal microscopy. Bars $10 \mu \mathrm{m}$. Panels at the right correspond to a magnification of the area indicated by white rectangles

to sorting and delivering of the membrane and cell wall materials required for IT progression.

Mutations in amino acids that are involved in the regulation of the RabA2 protein affected the progression of the infection events, but did not alter the total number of infections initiated in the root hairs (Fig. 3a, b). This phenotype points toward a role of RabA2 during elongation 


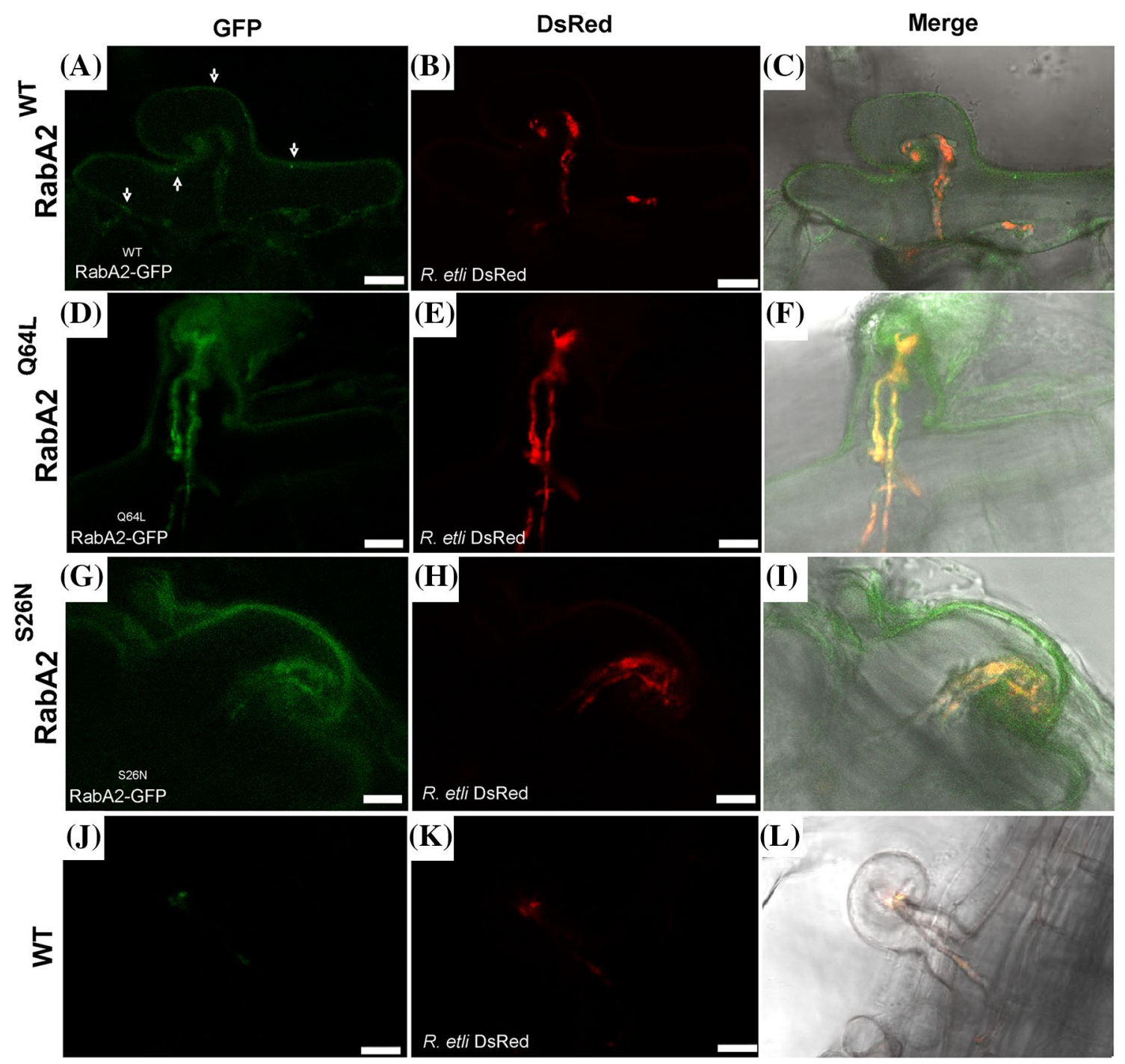

Fig. 6 GFP-RabA2 localizes around the IT. Confocal microscopy of root hairs with an IT on GFP-RabA2 ${ }^{\text {wt }}(\mathbf{a}-\mathbf{c})$, GFP-RabA2 ${ }^{\text {Q64L }}(\mathbf{d}-\mathbf{f})$ and GFP-RabA2 $2^{\mathrm{S} 26 \mathrm{~N}}(\mathbf{g}-\mathbf{i})$ roots inoculated with $R$. etli expressing DsRed at 8 DAI. Bars $10 \mu \mathrm{m}$. Images correspond to fluorescence of GFP (a, d, $\mathbf{g}, \mathbf{j})$, DsRed $(\mathbf{b}, \mathbf{e}, \mathbf{h}, \mathbf{k})$ or the merge of visible, GFP and

and maintenance of IT integrity, which is supported by the localization of the protein around this tubular structure (Fig. 6a-c). The protein with the highest sequence similarity to RabA2 in Arabidopsis thaliana is localized in the trans-Golgi compartment, possibly participating in the trafficking to the plasma membrane and the early endocytic pathway (Chow et al. 2008). The protein localizes at the margins of the Arabidopsis cell plate and seems to be required for cell division. The mutant versions S26N and Q71L (equivalent to the RabA2 $2^{\mathrm{S} 26 \mathrm{~N}}$ and $\mathrm{RabA2} 2^{\mathrm{Q} 64 \mathrm{~L}}$ mutations used in this work) changed their location to the cytosol, and in the first case, also to the Golgi. Previously, we have shown that vesicles labeled by RabA2 accumulated in the tip of the root hairs during normal growth and after
DsRed channels $(\mathbf{c}, \mathbf{f}, \mathbf{i}, \mathbf{l})$. Autofluorescence control was performed with a wild type root inoculated with the same $R$. etli strain expressing DsRed and fluorescence was scored with the same parameters used to visualize transgenic roots $(\mathbf{j}-\mathbf{l})$. Arrows in a indicate moving vesicles. Bars $10 \mu \mathrm{m}$

re-directioning produced by perception of rhizobia (Blanco et al. 2009). Here, we show that the protein localizes in mobile vesicles around the ITs and in cytoplasmic bridges that connect the plasma membrane with the IT membrane (Fig. 6 and Supplementary Fig. S4). Based on colocalization experiments with a Golgi molecular marker and the ArfA1 protein, we propose that vesicles labeled by GFPRabA2 belong to the Golgi/trans-Golgi network (Fig. 5). The strong colocalization of RabA2 and ArfA1 in the cytoplasm and in punctuates structures can indicate that they would be part of a GTPase cascade in a particular group of vesicles of the Golgi/trans Golgi. The partial colocalization with the late endosome/multivesicular bodies marker is in agreement with the previous results obtained for 
ArfA1 from barley and RabF2 in onion cells (Böhlenius et al. 2010). However, this result has been interpreted as a transitory state produced as a consequence of the transition of vesicles from early endosomes to multivesicular late endosomes (Robinson et al. 2011).

Subcellular localization of RabA2 depends on the GTP hydrolysis and GDP/GTP exchange, since mutations that affect these activities produce a change in the RabA2 subcellular localization (Fig. 6; Chow et al. 2008). In the case of Rab proteins, localization to the vesicle membranes is associated to the attachment of a geranylgeranyl group to a couple of cysteines in the C-terminus of the protein, and the binding of a GDP dissociation inhibitor (GDI). Displacement of GDI to expose the lipid is partially linked to the cycle of nucleotide hidrolysis (Grosshans et al. 2006). Thus, mutations that affect the GDP/GTP cycle result in a change of localization, as it has been reported for Rab proteins, as well as for monomeric GTPases of the Arf family (Xu and Shceres 2005; Limpens et al. 2009; Speth et al. 2009; Böhlenius et al. 2010). The negative effect of mutations that alters the hydrolysis of GTP and the GDP/GTP exchange can be related to the misslocalization observed for these mutants. On the other hand, GDP-locked versions are unable to interact with Rab effectors and GTP-locked variants interefere with progression of Rab cascades (Grosshans et al. 2006), altering in both cases the normal function of monomeric GTPases as molecular switches. Both the lack of switching between an active and inactive forms and/ or the misslocalization of mutated proteins might explain the deffects in rhizobial infection and nodule formation observed in roots expressing RabA2 ${ }^{\mathrm{S} 26 \mathrm{~N}}$ and $\mathrm{RabA} 2^{\mathrm{Q} 64 \mathrm{~L}}$. This regulatory system, based in GTP/GDP exchange and localization, contributes to explain the dominant or partially dominant nature of Q64L and S26N mutations, since these forms can remain associated to GTPase Activating Proteins (GAP) and Guanine nucleotide Exchange Factors (GEF) or GDI, avoiding the action of these proteins on wild type versions of GTPases.

RabA2 is also implicated in polar growth of the root hair. Mutations in the protein resulted in a reduction in the percentage of root hairs that curled in response to rhizobia (Supplementary Fig. 2c), but this phenotype was milder than that observed with RNAi of RabA2 (Blanco et al. 2009). This could be explained by the severe effect of the RNAi on the reduction of RabA2 transcript $(>95 \%)$ or by the partial dominance of the RabA2 $2^{\mathrm{Q} 64 \mathrm{~L}}$ and $\mathrm{RabA2} 2^{\mathrm{S} 26 \mathrm{~N}}$ variants over the wild type version of the protein. RabA2 $2^{\mathrm{Q} 64 \mathrm{~L}}$ and $\mathrm{RabA2} 2^{\mathrm{S} 26 \mathrm{~N}}$ roots developed small nodules that present early disintegration of symbiosome membranes (Fig. 2e, f), resembling that observed in senescent or ineffective nodules (Cermola et al. 2000). A similar effect on nodule senescence was originated by defects in the symbiosome formation by silencing of $R a b 7$ in $M$. truncatula (Limpens et al. 2009). It can also be proposed that the symbiosome membrane disintegration observed in roots expressing the RabA2 mutated forms could be a consequence of defects in symbiosome membrane formation. The observation that mutations in RabA2 also affected the integrity of IT membrane (Fig. 4; Table 1) is in favor of this hypothesis.

Infection by rhizobia via IT requires an actively growing root hair where polar growth is initiated from an infection chamber to form the tubular structure that guides bacteria toward cortical cells (Fournier et al. 2008, 2015). Cytoskeleton rearrangements are necessary during root hair growth and progression of IT inside the cell (Cárdenas et al. 1998; Yokota et al. 2009). As previously mentioned, Pirl and Napl genes are involved in actin dynamics and IT formation (Yokota et al. 2009). Interestingly, mutation of these genes produced defects in the infection process, resulting in abortive ITs that showed enlarged zones along the tubular structure, and the presence of rhizobia in the cytoplasm of epidermal cells. The protein encoded by Napl activates ARP2/3, a factor that regulates acting polymerization and branching (Miyahara et al. 2010). SCARN, a regulator of the APR $2 / 3$ complex, also blocked IT growth, resulting in early abortion in the root hair. Interestingly, some of the ITs produced in the scarn mutants grew within root hairs, whereas some others showed bacteria released into the cells. This phenotype is similar to that observed in $\mathrm{RabA2}{ }^{\mathrm{Q} 64 \mathrm{~L}}$ and $\mathrm{RabA2}{ }^{\mathrm{S} 26 \mathrm{~N}}$ roots (Fig. 4), and can be interpreted as the consequence of IT bursting. The M. truncatula ortholog of Napl is required not only for IT progression, but also for root hair polar growth (Miyahara et al. 2010). The phenotypic similarities observed between Napl mutants and roots expressing RabA2 mutants provides additional evidence of the importance of vesicle trafficking associated to actin cytoskeleton during polar growth of the root hair and assembling of the IT membrane. Taken together, these results indicate that IT integrity requires vesicle trafficking and actin rearrangements triggered by rhizobia, suggesting a connection between newly formed actin bundles with the transport of vesicles toward the elongating ITs. This transport of vesicle across microfilaments would support the continuous growth of ITs by providing enzymes and material required for the synthesis of membrane and cell wall (Lycett 2008). The pectate lyase NPL, which is specific of nodulation (Xie et al. 2012), or the cell wall protein ENOD11 (Fournier et al. 2015) are plausible cargos.

GTPases of the ROP family were proposed to regulate cytoskeletal rearrangement, influencing cell polarity, membrane transport and signaling in response to external stimuli (Yang and $\mathrm{Fu}$ 2007). ROP proteins also play a role in root hair growth and root nodule symbiosis in legumes. LjROP6 was identified as an interacting protein of the putative Nod 
factor receptor of Lotus japonicus NFR5 (Ke et al. 2012). The phenotype observed in LjRop6 RNAi roots is similar to that observed in RabA2 ${ }^{\mathrm{Q} 64 \mathrm{~L}}$ and $\mathrm{RabA} 2^{\mathrm{S} 26 \mathrm{~N}}$ roots in terms of the reduction in the percentage of ITs that reach cortical cells and the number of nodules formed. Similarly, $M t R O P 9$ silencing also resulted in a reduced number of ITs and nodules, but in this case the ROP protein had an additional role in polar growth of root hairs (Kiirika et al. 2012). Another ROP from M. truncatula, ROP10, is necessary for root hair polar growth. Defects in root hair formation produced by overexpression of ROP10 or a constitutively active form of this protein resulted in aberrant infections by S. meliloti (Lei et al. 2015). Localization of ROP proteins depends on the activity of other small GTPases and vesicle trafficking, as reported in the polar growth of root hairs (Molendijk et al. 2001; Xu and Scheres 2005). Therefore, it will be interesting to explore the connection between Rab and ROP proteins in the context of polar growth and infection events during root nodule symbiosis.

Penetration of bacteria to legume roots is a key step in terms of the specific recognition of compatible rhizobia during formation and progression of the IT. Our results, together with those reported by others, provide genetic support to the notion that the molecular machinery associated to vesicle trafficking and cytoskeleton rearrangements required for root hair polar growth has been co-opted to participate during the initial events of rhizobial infection, in particular, during root hair deformation and IT progression.

Acknowledgements We thank Claudio Mazo for technical assistance growing plants and Ing. Agr. Ricardo Ferreira for providing seeds.

Author contributions FB and MEZ conceived the work; VDV, ST, CR, MZ and FB executed and analyzed experiments; FB wrote the paper. All authors contributed to analysis of the data, revised and approved the final version of the manuscript

Funding This work was supported by grants from Agencia Nacional de Promoción Científica y Tecnológica, Argentina (PICT 2013/0384 and 2014/0321).

\section{Compliance with ethical standards}

Conflict of interest The authors declare that they have no conflict of interest.

\section{References}

Aguilar OM, Riva O, Peltzer Meschini E (2004) Analysis of Rhizobium etli and of its symbiosis with wild Phaseolus vulgaris supports coevolution in centers of host diversification. Proc Natl Acad Sci USA 101:13548-13553

Battaglia M, Rípodas C, Clúa J, Baudin M, Aguilar OM, Niebel A, Zanetti ME, Blanco FA (2014) A nuclear factor Y interacting protein of the GRAS family is required for nodule organogenesis, infection thread progression, and lateral root growth. Plant Physiol 164:1430-1442

Blanco FA, Peltzer Meschini E, Zanetti ME, Aguilar OM (2009) A small GTPase of the Rab family is required for root hair formation and preinfection stages of the common bean-Rhizobium symbiotic association. Plant Cell 21:2797-2810

Böhlenius H, Mørch SM, Godfrey D, Nielsen ME, Thordal-Christensen $\mathrm{H}$ (2010) The multivesicular body-localized GTPase ARFA1b/1c is important for callose deposition and ROR2 syntaxin-dependent preinvasive basal defense in barley. Plant Cell 22:3831-3844

Bond JE, Gresshoff PM (1993) Soybean transformation to study molecular physiology. In: Iacobellis NS, Collmer A, Hutcheson SW, Mansfield JW, Morris CE, Murillo J, Schaad NW, Stead DE, Surico G, Ullrich M (eds) Plant responses to the environment. Kluwer Academic CRC Presss, Dordrecht, pp 25-44

Cárdenas L, Vidali L, Domínguez J, Prez H, Sánchez F, Hepler PK, Quinto C (1998) Rearrangement of actin microfilaments in plant root hairs responding to Rhizobium etli nodulation signals. Plant Physiol 116:871-877

Catoira R, Timmers AC, Maillet F, Galera C, Penmetsa RV, Cook D, Denarie J, Gough C (2001) The HCL gene of Medicago truncatula controls Rhizobium-induced root hair curling. Development 128:1507-1518

Cermola M, Fedorova E, Tate R, Riccio A, Favre R, Patriarca EJ (2000) Nodule invasion and symbiosome differentiation during Rhizobium etli-Phaseolus vulgaris symbiosis. Mol Plant Microbe Interact 13:733-741

Cheon CI, Lee NG, Siddique AB, Bal AK, Verma DP (1993) Roles of plant homologs of Rab1p and Rab7p in the biogenesis of the peribacteroid membrane, a subcellular compartment formed de novo during root nodule symbiosis. EMBO J 12:4125-4135

Chow CM, Neto H, Foucart C, Moore I (2008) Rab-A2 and Rab-A3 GTPases define a trans-golgi endosomal membrane domain in Arabidopsis that contributes substantially to the cell plate. Plant Cell 20:101-123

Curtis MD, Grossniklaus U (2003) A gateway cloning vector set for high-throughput functional analysis of genes in planta. Plant Physiol 133:462-469

de Graaf BH, Cheung AY, Andreyeva T, Levasseur K, Kieliszewski M, Wu HM (2005) Rab11 GTPase-regulated membrane trafficking is crucial for tip-focused pollen tube growth in tobacco. Plant Cell 17:2564-2579

Esseling JJ, Lhuissier FG, Emons AM (2003) Nod factor-induced root hair curling: continuous polar growth towards the point of nod factor application. Plant Physiol 132:1982-1988

Estrada-Navarrete G, Alvarado-Affantranger X, Olivares JE, DiazCamino C, Santana O, Murillo E, Guillen G, Sanchez-Guevara N, Acosta J, Quinto C, Li D, Gresshoff PM, Sanchez F (2006) Agrobacterium rhizogenes transformation of the Phaseolus spp.: a tool for functional genomics. Mol Plant-Microbe Interact 19:1385-1393

Estrada-Navarrete G, Alvarado-Affantranger X, Olivares JE, Guillen G, Diaz-Camino C, Campos F, Quinto C, Gresshoff PM, Sanchez F (2007) Fast, efficient and reproducible genetic transformation of Phaseolus spp. by Agrobacterium rhizogenes. Nat Protoc 2:1819-1824

Fournier J, Timmers AC, Sieberer BJ, Jauneau A, Chabaud M, Barker DG (2008) Mechanism of infection thread elongation in root hairs of Medicago truncatula and dynamic interplay with associated rhizobial colonization. Plant Physiol 148:1985-1995

Fournier J, Teillet A, Chabaud M, Ivanov S, Genre A, Limpens E, de Carvalho-Niebel F, Barker DG (2015) Remodeling of the infection chamber before infection thread formation reveals a two-step mechanism for rhizobial entry into the host legume root hair. Plant Physiol 167:1233-1242 
Gage DJ (2004) Infection and invasion of roots by symbiotic, nitrogen-fixing rhizobia during nodulation of temperate legumes. Microbiol Mol Biol Rev 68:280-300

Grosshans BL, Ortiz D, Novick P (2006) Rabs and their effectors: achieving specificity in membrane traffic. Proc Natl Acad Sci USA 103:11821-11827

Hossain MS, Liao J, James EK, Sato S, Tabata S, Jurkiewicz A, Madsen LH Stougaard J, Ross L, Szczyglowski K (2012) Lotus japonicus ARPC1 is required for rhizobial infection. Plant Physiol 160:917-928

Ivanov S, Harrison MJ (2014) A set of fluorescent protein-based markers expressed from constitutive and arbuscular mycorrhiza-inducible promoters to label organelles, membranes and cytoskeletal elements in Medicago truncatula. Plant $\mathbf{J}$ 80:1151-1163

Jones MA, Shen JJ, Fu Y, Li H, Yang Z, Grierson CS (2002) The Arabidopsis Rop2 GTPase is a positive regulator of both root hair initiation and tip growth. Plant Cell 14:763-776

Jones KM, Kobayashi H, Davies BW, Taga ME, Walker GC (2007) How rhizobial symbionts invade plants: the SinorhizobiumMedicago model. Nat Rev Microbiol 5:619-633

Ke D, Fang Q, Chen C, Zhu H, Chen T, Chang X, Yuan S, Kang H, Ma L, Hong Z, Zhang Z (2012) The small GTPase ROP6 interacts with NFR5 and is involved in nodule formation in Lotus japonicus. Plant Physiol 159:131-143

Kiirika LM, Bergmann HF, Schikowsky C, Wimmer D, Korte J, Schmitz U, Niehaus K, Colditz F (2012) Silencing of the Rac1 GTPase MtROP9 in Medicago truncatula stimulates early mycorrhizal and oomycete root colonizations but negatively affects rhizobial infection. Plant Physiol 159:501-516

Lei M, Wang Q, Li X, Chen A, Luo L, Xie Y, Li G, Luo D, Mysore KS, Wen J, Xie Z, Staehelin C, Wang Y (2015) The small GTPase ROP10 of Medicago truncatula is required for both tip growth of root hairs and Nod Factor-induced root hair deformation. Plant Cell 27:806-822

Limpens E, Ivanov S, van Esse W, Voets G, Fedorova E, Bisseling T (2009) Medicago N2-Fixing symbiosomes acquire the endocytic identity marker Rab7 but delay the acquisition of vacuolar identity. Plant Cell 21:2811-2828

Lycett G (2008) The role of Rab GTPases in cell wall metabolism. J Exp Bot 59:4061-4074

Miyahara A, Richens J, Starker C, Morieri G, Smith L, Long S, Downie JA, Oldroyd G (2010) Conservation in function of a SCAR/WAVE component during infection thread and root hair growth in Medicago truncatula. Mol Plant-Microbe Interact 23:1553-1562

Molendijk AJ, Bischoff F, Rajendrakumar CS, Friml J, Braun M, Gilroy S, Palme K (2001) Arabidopsis thaliana Rop GTPases are localized to tips of root hairs and control polar growth. EMBO J 20:2779-2788

Murray JD, Muni RR, Torres-Jerez I, Tang Y, Allen S, Andriankaja M, Li G, Laxmi A, Cheng X, Wen J, Vaughan D, Schultze M, Sun J, Charpentier M, Oldroyd G, Tadege M, Ratet P, Mysore KS, Chen R, Udvardi MK (2011) Vapyrin, a gene essential for intracellular progression of arbuscular mycorrhizal symbiosis, is also essential for infection by rhizobia in the nodule symbiosis of Medicago truncatula. Plant J 65:244-252

Mustroph A, Zanetti ME, Jang CJ, Holtan HE, Repetti PP, Galbraith DW, Girke T, Bailey-Serres J (2009) Profiling translatomes of discrete cell populations resolves altered cellular priorities during hypoxia in Arabidopsis. Proc Natl Acad Sci USA 106:18843-18848

Nelson BK, Cai X, Nebenführ A (2007) A multicolored set of in vivo organelle markers for co-localization studies in Arabidopsis and other plants. Plant J 51:1126-1136
Oldroyd GE, Downie JA (2008) Coordinating nodule morphogenesis with rhizobial infection in legumes. Annu Rev Plant Biol 59:519-546

Peltzer Meschini E, Blanco FA, Zanetti ME, Beker MP, Kuster H, Puhler A, Aguilar OM (2008) Host genes involved in nodulation preference in common bean (Phaseolus vulgaris)-Rhizobium etli symbiosis revealed by suppressive subtractive hybridization. Mol Plant-Microbe Interact 21:459-468

Pimpl P, Movafeghi A, Coughlan S, Denecke J, Hillmer S, Robinson DG (2000) In situ localization and in vitro induction of plant COPI-coated vesicles. Plant Cell 12:2219-2235

Preuss ML, Serna J, Falbel TG, Bednarek SY, Nielsen E (2004) The Arabidopsis Rab GTPase RabA4b localizes to the tips of growing root hair cells. Plant Cell 16:1589-1603

Qiu L, Lin J, Xu J, Sato S, Parniske M, Wang TL, Downie A, Xie F (2015) SCARN a novel class of SCAR protein that is required for root-hair infection during legume Nodulation. PLoS Genet 11(10):e1005623

Rípodas C, Dalla Via V, Aguilar OM, Zanetti ME, Blanco FA (2013) Knock-down of a member of the isoflavone reductase gene family impairs plant growth and nodulation in Phaseolus vulgaris. Plant Physiol Biochem 68:81-89

Robinson DG, Scheuring D, Naramoto S, Friml J (2011) ARF1 localizes to the Golgi and the trans-Golgi network. Plant Cell 23:846-849

Sambrook J, Russel DW (2001) Molecular cloning: a laboratory manual. Cold Spring Harbour, New York

Speth EB, Imboden L, Hauck P, He SY (2009) Subcellular localization and functional analysis of the Arabidopsis GTPase RabE. Plant Physiol 149:1824-1837

Stefano G, Renna L, Chatre L, Hanton SL, Moreau P, Hawes C, Brandizzi F (2006) In tobacco leaf epidermal cells, the integrity of protein export from the endoplasmic reticulum and of ER export sites depends on active COPI machinery. Plant J 46:95-110

Surpin M, Raikhel N (2004) Traffic jams affect plant development and signal transduction. Nat Rev Mol Cell Biol 5:100-109

Takeuchi M, Ueda T, Yahara N, Nakano A (2002) Arf1 GTPase plays roles in the protein traffic between the endoplasmic reticulum and the Golgi apparatus in tobacco and Arabidopsis cultured cells. Plant J 31:499-515

Timmers AC, Auriac MC, Truchet G (1999) Refined analysis of early symbiotic steps of the Rhizobium-Medicago interaction in relationship with microtubular cytoskeleton rearrangements. Development 126:3617-3628

van Brussel AA, Bakhuizen R, van Spronsen PC, Spaink HP, Tak T, Lugtenberg BJ, Kijne JW (1992) Induction of pre-infection thread structures in the leguminous host plant by mitogenic lipooligosaccharides of Rhizobium. Science 257:70-72

Xie F, Murray JD, Kim J, Heckmann AB, Edwards A, Oldroyd GE, Downie JA (2012) Legume pectate lyase required for root infection by rhizobia. Proc Natl Acad Sci USA 109:633-638

$\mathrm{Xu}$ J, Scheres B (2005) Dissection of Arabidopsis ADP-RIBOSYLATION FACTOR 1 function in epidermal cell polarity. Plant Cell 17:525-536

Yang Z, Fu Y (2007) ROP/RAC GTPase signaling. Curr Opin Plant Biol 10:490-494

Yokota K, Fukai E, Madsen LH, Jurkiewicz A, Rueda P, Radutoiu S, Held M, Hossain MS, Szczyglowski K, Morieri G, Oldroyd GE, Downie JA, Nielsen MW, Rusek AM, Sato S, Tabata S, James EK, Oyaizu H, Sandal N, Stougaard J (2009) Rearrangement of actin cytoskeleton mediates invasion of Lotus japonicus roots by Mesorhizobium loti. Plant Cell 21:267-284

Zanetti ME, Blanco FA, Beker MP, Battaglia M, Aguilar OM (2010) A C subunit of the plant nuclear factor NF-Y required for rhizobial infection and nodule development affects partner 
selection in the common bean-Rhizobium etli symbiosis. Plant Cell 22:4142-4157

Zheng H, Camacho L, Wee E, Batoko H, Legen J, Leaver CJ, Malhó R, Hussey PJ, Moore I (2005) A Rab-E GTPase mutant acts downstream of the Rab-D subclass in biosynthetic membrane traffic to the plasma membrane in tobacco leaf epidermis. Plant Cell 17:2020-2036 